\title{
A proposed algorithm for combining transcranial Doppler ultrasound monitoring with cerebral and somatic oximetry: a case report
}

\section{Proposition d'un algorithme combinant le monitorage échographique par Doppler transcrânien à l'oxymétrie cérébrale et somatique : une présentation de cas}

\author{
Milène A. Azzam, MD • Etienne J. Couture, MD • William Beaubien-Souligny, MD • \\ Patrice Brassard, PhD • Caroline E. Gebhard, MD • André Y. Denault, MD, PhD (D)
}

Received: 26 May 2020/Revised: 11 August 2020/Accepted: 5 October 2020/Published online: 15 October 2020

(C) Canadian Anesthesiologists' Society 2020

\begin{abstract}
Purpose Transcranial Doppler (TCD) ultrasound is a non-invasive monitor of cerebral blood velocity that can be used intraoperatively. The purpose of this report is to describe how different patterns seen on TCD can help identify the cause of cerebral desaturation when nearinfrared spectroscopy (NIRS) oximetry is used concomitantly.

Clinical features A 69-yr-old male patient undergoing coronary revascularisation and aortic valve replacement developed perioperative complications that were detected using a combination of transtemporal TCD of the middle cerebral artery along with cerebral and somatic NIRS.
\end{abstract}

M. A. Azzam, MD

Department of Anesthesiology, Montreal Heart Institute, Université de Montréal, 5000 Belanger Street, Montreal, QC H1T 1C8, Canada

E. J. Couture, MD

Department of Anesthesiology and Critical Care Division, Quebec Heart and Lung Institute, Quebec, QC, Canada

W. Beaubien-Souligny, MD

Department of Anesthesiology, Montreal Heart Institute, Université de Montréal, 5000 Belanger Street, Montreal, QC H1T 1C8, Canada

Department of Nephrology, Centre Hospitalier de l'Université de Montréal, Montreal, QC, Canada

P. Brassard, $\mathrm{PhD}$

Department of Kinesiology, Faculty of Medicine, Research Center, Institut universitaire de cardiologie et de pneumologie de Québec, Université Laval, Quebec, QC, Canada
Initial brain desaturation was secondary to hypocapnia during which TCD-derived blood velocity and somatic NIRS values remained unchanged. After the procedure, a second episode of brain desaturation occurred secondary to a technical issue with the aortic valve prosthesis requiring a return to cardiopulmonary bypass (CPB); there were no high-intensity transient signals (HITS) on $T C D$. Brain desaturation occurred a third time following the second attempt to separate from $C P B$ at which time TCD detected a significant amount of HITS suggesting air emboli that were associated with acute right ventricular dysfunction; there was also a reduction in somatic NIRS.

\section{E. Gebhard, MD}

Department of Intensive Care Medicine, University Hospital of Basel, Basel, Switzerland

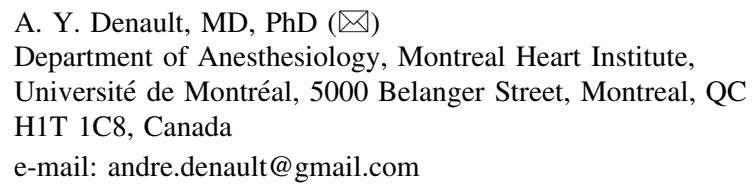

Critical Care Division, Montreal Heart Institute, Université de Montréal, Montreal, QC, Canada 
Conclusions Combining TCD with cerebral NIRS allows for the rapid identification of three different mechanisms of brain desaturation. An algorithm is proposed to help identify the origin of NIRS cerebral desaturation. Prospective clinical trials are needed to investigate potential benefits of multimodal brain monitoring and its impact on short and/or long-term clinical outcomes.

\section{Résumé}

Objectif L'échographie par Doppler transcrânien (DTC) est un moniteur non invasif de la velocité sanguine cérébrale qui peut être utilisé en période peropératoire. L'objectif de ce compte rendu est de décrire comment différents tracés observés sur le DTC peuvent aider l'anesthésiologiste à identifier la cause de la désaturation cérébrale lorsque l'oxymétrie par spectroscopie proche infrarouge (SPIR) est utilisée de manière concomitante.

Éléments cliniques Un homme de 69 ans subissant une revascularisation coronarienne et un remplacement de valve aortique a présenté des complications périopératoires détectées grâce à la combinaison d'un DTC trans-temporal de l'artère cérébrale moyenne et d'une SPIR cérébrale et somatique. La désaturation cérébrale initiale était secondaire à une hypocapnie, pendant laquelle la velocité sanguine dérivée du DTC et les valeurs de SPIR somatique sont demeurées inchangées. Après l'intervention, un deuxième épisode de désaturation cérébrale est survenu suite à un problème technique avec la prothèse de valve aortique, nécessitant un retour sous circulation extracorporelle (CEC); il n'y avait pas de signaux transitoires de haute intensité (HITS) sur le DTC. Il y a eu un troisième épisode de désaturation cérébrale suite à la deuxième tentative de sevrage de la CEC; à ce moment-là, le DTC a détecté une quantité significative de HITS, suggérant des embolies gazeuses associées à une insuffisance ventriculaire droite aiguë; une réduction de la SPIR somatique a également été observée.

Conclusion La combinaison du DTC à la SPIR cérébrale a permis d'identifier trois différents mécanismes de désaturation cérébrale. Un algorithme est proposé pour aider le clinicien à déterminer l'origine de la désaturation cérébrale sur la SPIR. Des études cliniques prospectives sont nécessaires afin d'explorer les avantages potentiels d'un monitorage cérébral multimodal et son impact sur les devenirs cliniques à court et à long terme.

Keywords transcranial Doppler .

near-infrared spectroscopy $\cdot$ case report

Transcranial Doppler ultrasound (TCD) is a non-invasive technique to monitor cerebral blood velocities and to detect high-intensity transient signals (HITS) that represent cerebral embolic events. ${ }^{1}$ Monitoring of patients undergoing carotid endarterectomy using a combination of TCD and cerebral near-infrared spectroscopy (NIRS) has previously been reported, ${ }^{2}$ and both modalities can also be used to evaluate cerebral autoregulation. ${ }^{3}$ At the author's institution, TCD monitoring is increasingly used, particularly in complex cardiac surgeries, in addition to our routine monitoring with NIRS for all patients undergoing cardiac surgery on cardiopulmonary bypass. Herein, we report the concomitant use of TCD and NIRS in a patient who underwent complex cardiac surgery. Cerebral and somatic NIRS were combined with TCD to identify three different mechanisms of cerebral oxygen desaturation. An algorithm to treat desaturation using TCD combined with cerebral and somatic NIRS is proposed to address the various causes of desaturation in different clinical situations.

\section{Case presentation}

A 69-yr-old man with significant coronary artery disease, severe aortic valve (AV) insufficiency, left ventricular (LV) dilatation, and an LV ejection fraction of 35\% underwent coronary revascularisation and $\mathrm{AV}$ replacement. Written informed consent for this report was obtained from the patient. Prior to induction of anesthesia, standard anesthesia monitors, ${ }^{4}$ radial artery catheter, bifrontal cerebral and somatic NIRS (baseline value $72 \%$ on the right brain and $73 \%$ on the right thigh) (Nonin Medical Inc., Plymouth, MN, USA), and processed electroencephalography (Sedline Masimo, Irvine, CA, USA) were utilized for this patient. Transcranial Doppler ultrasound monitoring of the middle cerebral artery (ST3 Digital Transcranial Doppler System, Model PMD 150, Spencer Technologies, Seattle, WA, USA) was installed after adequate localization of the circle of Willis using color Doppler mode of the handheld ultrasound device as previously described. ${ }^{5}$ Following anesthesia induction, central venous, pulmonary artery (PA), and femoral artery catheters were inserted. Hemodynamic monitoring initially indicated significant pulmonary hypertension and an abnormal right ventricular (RV) diastolic pressure waveform (Fig. 1a). ${ }^{6}$ A transesophageal echocardiography (TEE) exam performed prior to cardiopulmonary bypass (CPB) confirmed diffuse LV hypokinesis and RV dysfunction. Abdominal ultrasonography examination using TEE showed $>50 \%$ portal vein pulsatility (Fig. 1b). ${ }^{7,8}$ Upon initiation of CPB, cerebral NIRS saturation decreased by $18 \%$ relative to baseline, while somatic NIRS saturation values remained stable, secondary to inadvertent hypocapnia (Fig. 1c) with 


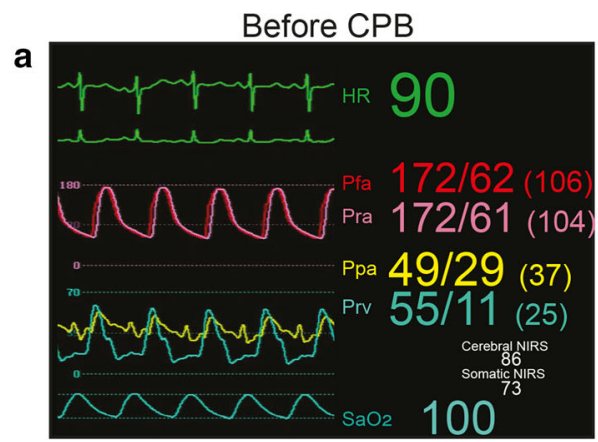

During CPB

C

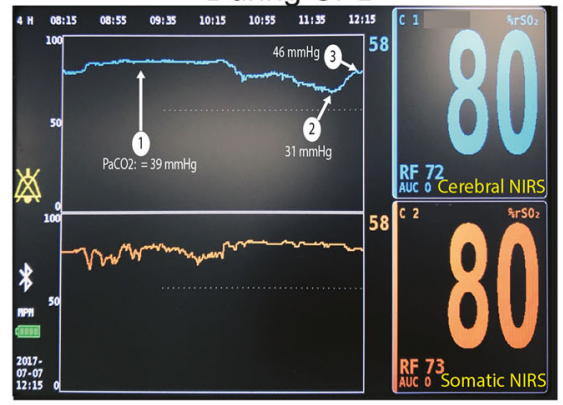

After separation from 1st CPB

e

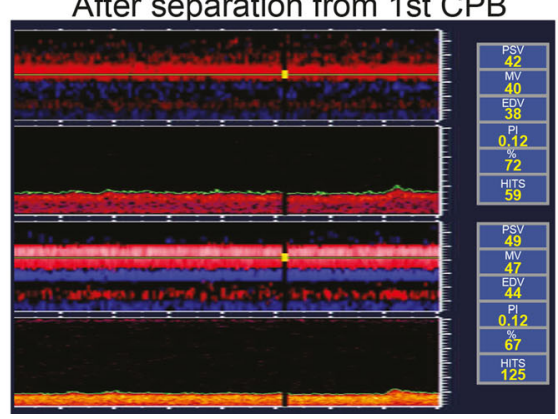

Fig. 1 (A) Hemodynamic parameters prior to cardiopulmonary bypass (CPB). Pulmonary and systemic hypertension is present, with an abnormal systemic-to-pulmonary mean arterial pressure ratio $(106 / 37=2.9$; normal $>4) .{ }^{23}$ The right ventricular $(\mathrm{RV})$ pressure waveform (Prv, blue trace) shows an abnormal diastolic slope suggesting RV diastolic dysfunction. ${ }^{6}$ (B) Significant portal vein pulsatility $([19 \mathrm{~cm} / \mathrm{s}-9 \mathrm{~cm} / \mathrm{s}] / 19 \mathrm{~cm} / \mathrm{s}=52 \% \text {; normal }<30 \%)^{8}$ was present in this patient initially. (C) Cerebral and somatic oxygen saturation monitoring using near-infrared spectroscopy (NIRS) during $\mathrm{CPB}$. Baseline cerebral saturation was $72 \%$ on the right brain and somatic saturation $73 \%$ on the right thigh with an arterial carbon dioxide partial pressure $\left(\mathrm{PaCO}_{2}\right)$ of $39 \mathrm{mmHg}$ (point 1). Cerebral desaturation to $66 \%$ upon initiation of $\mathrm{CPB}$ with unchanged somatic value (point 2) pointed to hypocapnia $\left(\mathrm{PaCO}_{2}\right.$ of $\left.31 \mathrm{mmHg}\right)$ as seen on subsequent arterial blood gas analysis; ventilation was corrected and the cerebral saturation returned to baseline (point 3; $\mathrm{PaCO}_{2}$ of 45 $\mathrm{mmHg}$ ). (D) Hemodynamic parameters and transtemporal

no significant changes in TCD signals. The initial arterial carbon dioxide partial pressure $\left(\mathrm{PaCO}_{2}\right)$ was $39 \mathrm{mmHg}$ and decreased to $31 \mathrm{mmHg}$ during brain desaturation. Reducing ventilation corrected the hypocapnia and restored the $\mathrm{PaCO}_{2}$ to $45 \mathrm{mmHg}$. During the first weaning attempt, a significant $25 \mathrm{mmHg}$ radial-to-femoral mean arterial pressure (MAP) gradient occurred (Fig. 1d). Upon

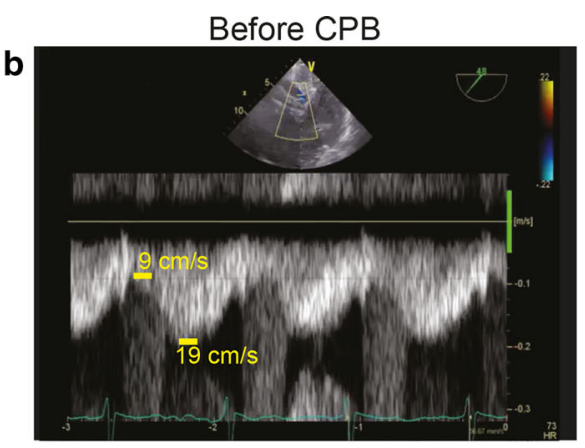

After separation from 1st CPB

d
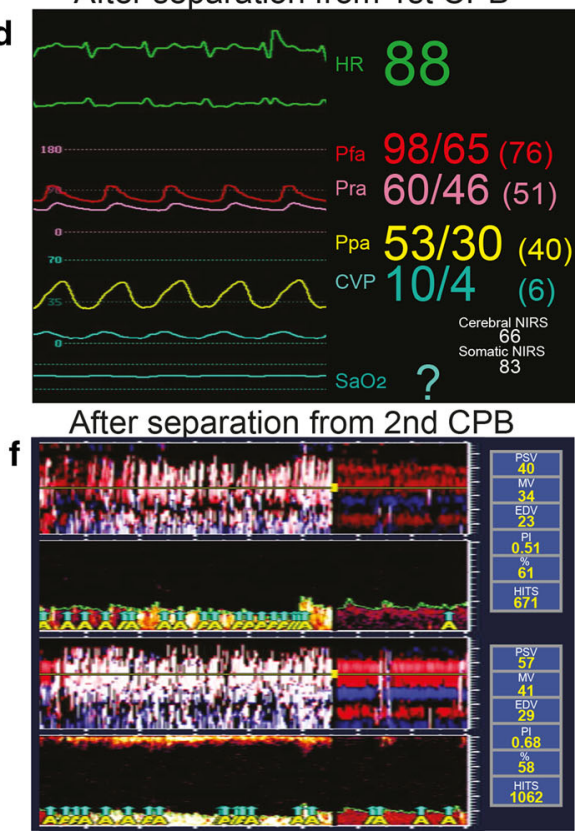

transcranial Doppler (TCD) ultrasound monitoring of both middle cerebral artery (MCA) blood velocities (E) during the first CPB weaning attempt. Note the significant gradient (mean of $25 \mathrm{mmHg}$ ) between the mean femoral arterial pressure (Pfa) and radial arterial pressure (Pra). The increase in the pulmonary artery pressure (Ppa) was secondary to aortic prosthetic valvular dysfunction. Transtemporal TCD velocities of both MCA after the first (E) and second $(\mathrm{F})$ separation from CPB. Note the absence of high-intensity transient signals (HITS) upon the first weaning attempt. (F) A significant increase in HITS was present upon the second weaning attempt. This preceded the development of right ventricular dysfunction and implicated air embolization to the right coronary artery. $\mathrm{AUC}=$ area under the curve; $\mathrm{CVP}=$ central venous pressure; $\mathrm{EDV}=$ end-diastolic velocity; $\mathrm{HR}=$ heart rate; $\mathrm{MV}=$ mean velocity; $\mathrm{PaCO}_{2}=$ arterial carbon dioxide partial pressure; $\mathrm{PI}=$ pulsatility index; PSV = peak systolic velocity; $\mathrm{RF}=$ baseline reference value; $\mathrm{SaO}_{2}=$ arterial oxygen saturation

weaning from CPB, a second episode of cerebral NIRS desaturation occurred and was associated with an abnormally elevated PA pressure without any appearance of HITS on the TCD exam (Fig. 1e). A TEE examination revealed significant insufficiency of the bioprosthetic AV, which resulted in immediate return to CPB. An AV leaflet restriction by an aberrant stitch on the bioprosthetic leaflet 
Fig. 2 Transcranial Dopplerderived blood velocity (A) before and (B) after aortic valve repair (AVR) in a 69-yr-old man with severe chronic aortic regurgitation. Note the reduced end-diastolic velocities (EDV) and the elevated pulsatility index (PI) from 1.86 and 2.04 (normal: 0.8-1.2) in the left and right middle cerebral artery which normalized after AVR (C) Simultaneously obtained splenic artery Doppler velocities from a transgastric abdominal ultrasound. Note the reversed diastolic velocities (arrows) before AVR. (D) After AVR, increased diastolic velocities were observed. $\%=$ percentage mean velocity (MV) values compared with baseline; ESV = end-systolic velocity; PSV = peak systolic velocity; HITS = high-intensity transient signals a
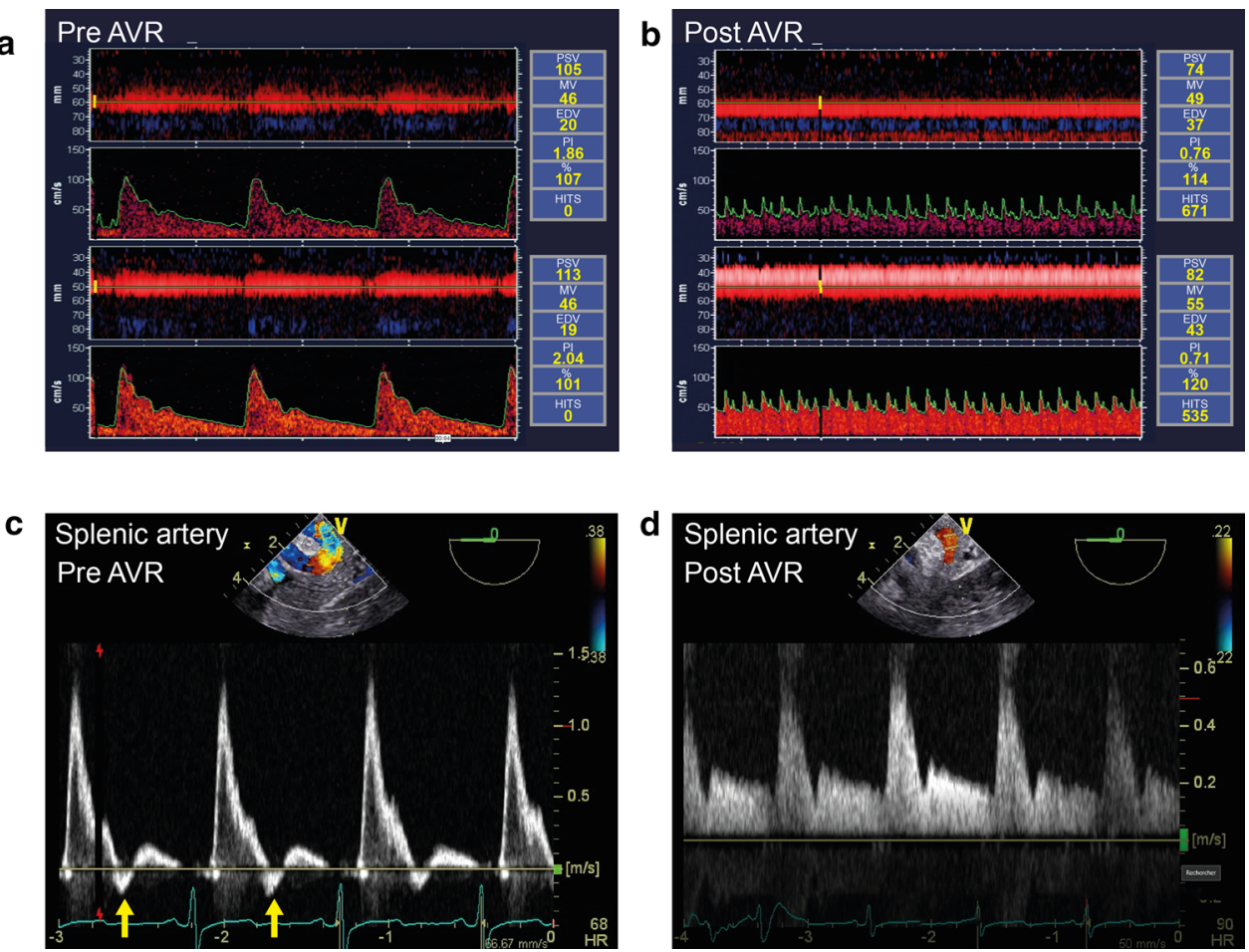

was identified as the underlying etiology and was repaired. Transesophageal echocardiography examination during the second CPB weaning attempt showed resolution of AV insufficiency. Nevertheless, a third cerebral NIRS desaturation episode occurred with new onset of severe RV dysfunction and a large amount of residual air in the LV. At that time, TCD monitoring showed numerous HITS (Fig. 1f) and the somatic NIRS was reduced. Cardiopulmonary bypass was resumed a third time and intratracheal milrinone $(5 \mathrm{mg}$ ) was administered to support RV function. ${ }^{9}$ The patient was finally weaned from CPB using $0.1 \mu \mathrm{g} \cdot \mathrm{kg}^{-1} \cdot \mathrm{min}^{-1}$ epinephrine, $0.3 \mu \mathrm{g} \cdot \mathrm{kg}^{-1} \cdot \mathrm{min}^{-1}$ norepinephrine, and $2.4 \mathrm{U} \cdot \mathrm{hr}^{-1}$ vasopressin.

\section{Discussion}

This case shows the utility of combining TCD with cerebral and somatic NIRS. Initially, the isolated cerebral desaturation that we saw was secondary to excessive ventilation resulting in hypocapnia. In that situation, somatic NIRS was normal indicating that the problem was affecting cerebral vasculature and was not from a systemic low flow state. Although hypocapnia has been associated with a reduction in mean cerebral blood velocity from 2.5 to $3.9 \%$ per $\mathrm{mmHg},{ }^{10}$ those TCD changes are not as easily detected as they are with NIRS, as this amount of change is within the variation that can be seen depending on other cerebral autoregulation factors. ${ }^{11}$ On the other hand, if both cerebral and somatic desaturation occur, then a systemic low flow state such as heart failure or bleeding should be expected as the underlying etiology. In a systemic low flow situation, both cerebral blood flow estimated from TCD velocities and NIRS would have been reduced. $^{12}$ In our experience, air emboli detected by TCD will often be observed before RV failure becomes apparent on TEE examination, as in the current case, or before the appearance of electrocardiographic changes of ischemia. ${ }^{13}$ Preferential embolization of air in the right coronary artery can be explained by the non-dependent position of its ostium in the aortic root. Cerebral hypoperfusion would be suspected if mean, systolic, and diastolic cerebral blood velocities of the middle cerebral artery are reduced as opposed to venous congestion where only diastolic cerebral blood velocities will be attenuated with the systolic values remaining unchanged. ${ }^{14}$ During venous congestion and elevation in central venous pressure, diastolic cerebral blood velocity from TCD will be reduced and the pulsatility index ([systolic velocities - diastolic velocities]/mean velocities) (normal: 0.81-0.97) increased, ${ }^{10,15}$ with reductions in both cerebral and somatic NIRS values. Similar signals will be observed 


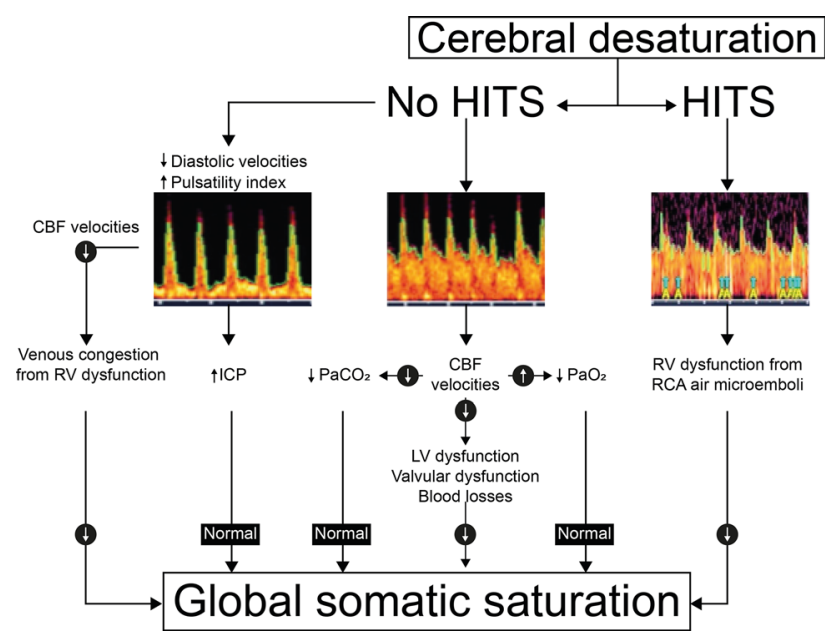

Fig. 3 Proposed approach to the use of transcranial Doppler (TCD) ultrasound together with cerebral and somatic near infrared spectroscopy (NIRS). If brain desaturation occurs in conjunction with a high burden of high-intensity transient signal (HITS), this may lead to right ventricular (RV) dysfunction from embolization into the right coronary artery (RCA). In that situation, global somatic desaturation will also be observed. If brain desaturation occurs without HITS, then the cerebral blood velocities and pulsatility index (PI) should be examined. Hypoxemia or reduction in arterial oxygen partial pressure $\left(\mathrm{PaO}_{2}\right)$ will be typically associated with normal or elevated cerebral blood velocity values. ${ }^{24}$ Reduction in cerebral blood velocities will be observed during hypocapnia or reduction in arterial carbon dioxide partial pressure $\left(\mathrm{PaCO}_{2}\right)$ but also in situations where cardiac output is reduced such as left ventricular (LV) dysfunction, acute valvular heart disease, and blood loss. An increase in PI can be associated with elevated intracranial pressure (ICP) or with elevation of the central venous pressure. ${ }^{14-16,25,26}$ Global somatic desaturation will be present if the reduced TCD diastolic velocity and elevated PI is secondary to venous congestion. Nevertheless, global somatic saturation will be normal or maintained if the mechanism of brain desaturation, reduced TCD diastolic velocity, and elevated PI is secondary to intracranial hypertension. An exception would be superior vena cava syndrome in which case the somatic saturation from upper extremity would be reduced but normal in the lower extremity. ${ }^{12,14} \mathrm{CBF}=$ cerebral blood flow

with intracranial hypertension, ${ }^{16}$ although somatic NIRS values would remain normal. Chronic aortic regurgitation with reduced aortic diastolic pressure can also be associated with elevated pulsatility index regardless of NIRS value. ${ }^{17}$ When combined cerebral and somatic NIRS desaturations occur, the mechanism is not cerebral. Similarly, TCD can also be interpreted with both cerebral and somatic values (Fig. 2). If Doppler interrogation of a somatic artery like the splenic artery (Fig. 2c) ${ }^{13}$ shows reduced diastolic blood velocity and elevated pulsatility index, then the abnormal cerebral TCD is not the result of an intracranial process but could be secondary to chronic aortic regurgitation, for example. Finally, if both the NIRS and TCD signals are normal but the radial arterial pressure is reduced, pseudo radial hypotension could explain this situation, as encountered here after the first weaning attempt. ${ }^{18}$ Systolic radial-to-femoral gradients $\geq 25 \mathrm{mmHg}$ and MAP gradients $\geq 10 \mathrm{mmHg}$ can be observed in one third of cardiac surgical patients. ${ }^{19}$ A proposed approach of combining cerebral and somatic NIRS to TCD is summarized in Fig. 3. Further validation in a larger patient cohort is required.

There are, however, limitations in using brain monitoring modalities, particularly when different mechanisms of brain desaturation can occur simultaneously such as bleeding and right heart failure. For instance, air emboli in the right coronary artery do not always result in acute RV failure. If the acute RV failure is severe and associated with reduced cardiac output, then both systolic and diastolic TCD velocities might be proportionally reduced with minimal change in the pulsatility index. In RV dysfunction with preserved LV systolic function, the elevation in venous pressure may result in a decrease in the diastolic TCD velocities and an increase in the pulsatility index. The use of TCD in cardiac surgery is limited by the experience of the operator, availability of the equipment, and the presence of a suitable transtemporal cerebral acoustic window. We have previously described a technique using point-of-care ultrasound with two-dimensional imaging of the brain to identify the window prior to positioning TCD monitoring. ${ }^{5}$ In 95 out of 100 patients, we were able to identify at least an adequate unilateral window. Compared with NIRS and processed electroencephalography, monitoring with TCD is reusable as with any ultrasound machine. Newer NIRS modalities that can identify oxy and deoxy hemoglobin could represent an alternative to TCD in identifying the mechanism of brain desaturation ${ }^{20}$ (Fig. 4). Nevertheless, they do not detect HITS and their ability to identify the exact mechanism of brain desaturation, though promising, remains to be shown. Finally, outcome studies would be necessary to document the usefulness of this type of monitoring strategy and algorithm. The word monitoring comes from the latin word "monere", which means "warning". Pederson et al., in a Cochrane review reported that the value of perioperative monitoring with pulse oximetry is questionable ${ }^{21}$ despite the fact that it is a standard of care in anesthesia practice. ${ }^{4}$ The use of TEE has been relatively routine in cardiac surgery for more than 20 years. Only recently, however, were favourable outcomes from its use seen in a study of 219,238 valve surgery patients. ${ }^{22}$ Therefore, it is unlikely that TCD will be studied in sufficient numbers to clearly be associated with improvement in overall outcomes. We use TCD in the operating room and in the intensive care unit as a warning device to detect unilateral or bilateral brain malperfusion, venous hypertension, intracranial hypertension, air embolism or HITS, and as a complement to oximetry and 


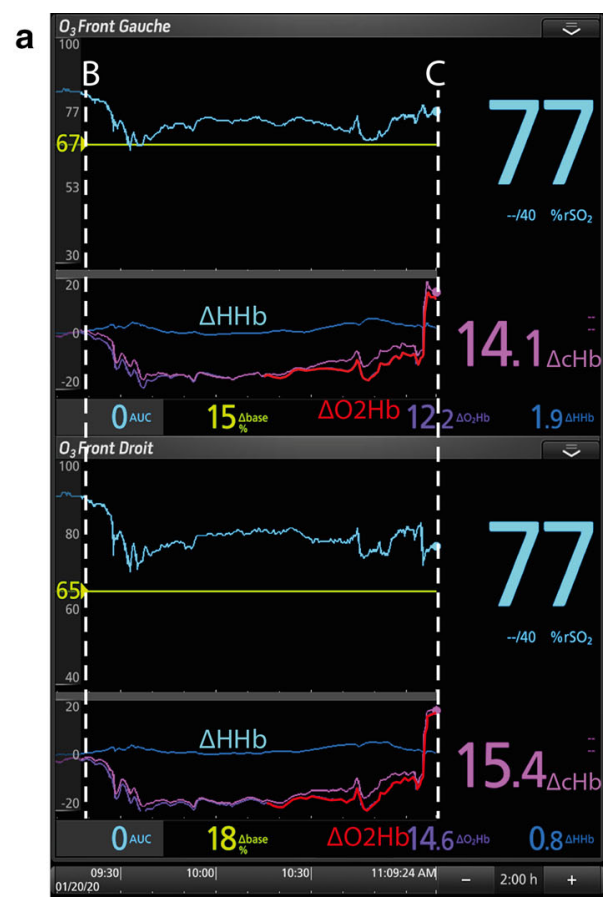

Fig. 4 Near-infrared spectroscopy (NIRS) and transcranial Doppler in a 65-year-old man undergoing aortic valve replacement. (A) The baseline NIRS values were $67 \%$ on the left and $65 \%$ on the right. The NIRS components are displayed and include oxyhemoglobin $\left(\Delta \mathrm{O}_{2} \mathrm{Hb}\right)$ in red and deoxyhemoglobin $(\Delta \mathrm{HHb})$ in blue, the sum of which equals the total cerebral hemoglobin $(\Delta \mathrm{cHb})$ in pink. Note that at the end of the case, the overall brain saturation (77\% on both sides) was higher than at the beginning. This was associated with an increase in $\Delta \mathrm{O}_{2} \mathrm{Hb}$ on both sides. The transtemporal TCD velocities of the middle cerebral arteries at the beginning (B) and at the end (C) are

processed electroencephalographic monitoring. Each of these brain monitors provides different and complementary information to safeguard brain function.

In summary, combining cerebral and somatic NIRS to TCD in a multimodal neurologic monitoring approach allows continuous monitoring during complex cardiac surgery, providing the possibility for instantaneous and targeted treatments to better understand cerebral physiology and eventually improve patient outcome.

Author contributions Milène A. Azzam and André Y. Denault contributed to all aspects of this manuscript, including study conception and design; acquisition, analysis, and interpretation of data; and drafting the article. All authors contributed to the conception and design of the study and interpretation of data.

Disclosures Dr. Denault is a speaker for CAE Healthcare (2010) and Masimo (2017). He received equipment grant from Edwards (2019). Dr. Gebhard was supported by grants from the Forschungsverein Anästhesie and Intensive Care Medicine, University Hospital Basel and the Nachwuchsförderung Klinische Forschung of the University of Basel, Switzerland. The other authors have no conflicts of interest to declare.
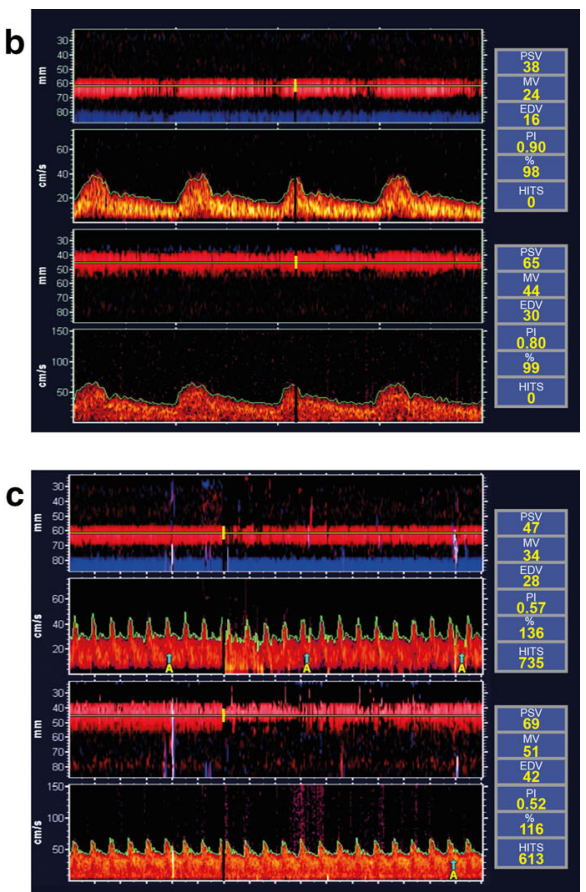

displayed. The TCD velocities and the percentage of velocities compared with baseline were also higher at the end of the case. This suggests that the higher NIRS values were associated with higher $\Delta \mathrm{cHb}$ as a result of elevated $\Delta \mathrm{O}_{2} \mathrm{Hb}$. The higher TCD velocities and $\Delta \mathrm{O}_{2} \mathrm{Hb}$ suggest increased cerebral blood flow. AUC $=$ area under the curve; $\mathrm{EDV}=$ end-diastolic velocities; HITS = high-intensity transient signals; $\mathrm{MV}=$ mean velocities; $\mathrm{PI}=$ pulsatility index; PSV $=$ peak systolic velocities; $\Delta$ base $=$ NIRS value in relation to baseline; $\Delta \mathrm{SpO}_{2}=$ change in pulse oximetry

Funding statement None.

Editorial responsibility This submission was handled by Dr. Hilary P. Grocott, Editor-in-Chief, Canadian Journal of Anesthesia.

\section{References}

1. Weyland A, Stephan H, Kazmaier S, et al. Flow velocity measurements as an index of cerebral blood flow. Validity of transcranial Doppler sonographic monitoring during cardiac surgery. Anesthesiology 1994; 81: 1401-10.

2. Grubhofer G, Plochl W, Skolka M, Czerny M, Ehrlich $M$, Lassnigg A. Comparing Doppler ultrasonography and cerebral oximetry as indicators for shunting in carotid endarterectomy. Anesth Analg 2000; 91: 1339-44.

3. Ono $M$, Zheng $Y$, Joshi B, Sigl JC, Hogue $C W$. Validation of a stand-alone near-infrared spectroscopy system for monitoring cerebral autoregulation during cardiac surgery. Anesth Analg 2013; 116: 198-204.

4. Dobson G, Chow L, Filteau L, et al. Guidelines to the practice of anesthesia - revised edition 2020. Can J Anesth 2020; 67: 64-99.

5. Couture EJ, Desjardins G, Denault AY. Transcranial Doppler monitoring guided by cranial two-dimensional ultrasonography. Can J Anesth 2017; 64: 885-7. 
6. Raymond M, Gronlykke L, Couture EJ, et al. Perioperative right ventricular pressure monitoring in cardiac surgery. J Cardiothorac Vasc Anesth 2019; 33: 1090-104.

7. Denault AY, Beaubien-Souligny W, Elmi-Sarabi M, et al. Clinical significance of portal hypertension diagnosed with bedside ultrasound after cardiac surgery. Anesth Analg 2017; 124: 1109-15.

8. Eljaiek $R$, Cavayas YA, Rodrigue E, et al. High postoperative portal venous flow pulsatility indicates right ventricular dysfunction and predicts complications in cardiac surgery patients. Br J Anaesth 2019; 122: 206-14.

9. Gebhard CE, Rochon A, Cogan J, et al. Acute right ventricular failure in cardiac surgery during cardiopulmonary bypass separation: a retrospective case series of 12 years' experience with intratracheal milrinone administration. J Cardiothorac Vasc Anesth 2019; 33: 651-60.

10. Doblar DD, Lim YC, Frenette L, Poplawski S, Ranjan D, Ronderos $J$. The effect of acute hypocapnia on middle cerebral artery transcranial Doppler velocity during orthotopic liver transplantation: changes at reperfusion. Anesth Analg 1995; 80: 1194-8.

11. Widder $B$. The Doppler $\mathrm{CO} 2$ test to exclude patients not in need of extracranial/intracranial bypass surgery. J Neurol Neurosurg Psychiatry 1989; 52: 38-42.

12. Denault A, Shaaban Ali M, Couture EJ, et al. A practical approach to cerebro-somatic near-infrared spectroscopy and whole-body ultrasound. J Cardiothorac Vasc Anesth 2019; 33(Suppl 1): S11-37.

13. Denault A, Haddad F, Lamarche Y, Bouabdallaoui N, Deschamps $A$, Desjardins $G$. Postoperative right ventricular dysfunctionintegrating right heart profiles beyond long-axis function. $\mathrm{J}$ Thorac Cardiovasc Surg 2020; 159: e315-7.

14. Couture EJ, Deschamps A, Denault AY. Patient management algorithm combining processed electroencephalographic monitoring with cerebral and somatic near-infrared spectroscopy: a case series. Can J Anesth 2019; 66: 532-9.

15. Lahiri S, Schlick KH, Padrick MM, et al. Cerebral pulsatility index is elevated in patients with elevated right atrial pressure. $\mathrm{J}$ Neuroimaging 2018; 28: 95-8.

16. Gura M, Elmaci I, Sari R, Coskun N. Correlation of pulsatility index with intracranial pressure in traumatic brain injury. Turk Neurosurg 2011; 21: 210-5.
17. Lovrencic-Huzjan A, Jurasic MJ, Lovrencic-Prpic G, Vukovic V, Demarin $V$. Aortic arch dissection presenting with hemodynamic spectrum of aortic regurgitation on transcranial Doppler. Ultraschall Med 2006; 27: 280-3.

18. Fuda G, Denault A, Deschamps A, et al. Risk factors involved in central-to-radial arterial pressure gradient during cardiac surgery. Anesth Analg 2016; 122: 624-32.

19. Bouchard-Dechene $V$, Couture $P, S u$ A, et al. Risk factors for radial-to-femoral artery pressure gradient in patients undergoing cardiac surgery with cardiopulmonary bypass. J Cardiothorac Vasc Anesth 2018; 32: 692-8.

20. Shaaban-Ali M, Momeni M, Denault A. Clinical and technical limitations of cerebral and somatic near-infrared spectroscopy as an oxygenation monitor. J Cardiothorac Vasc Anesth 2020; DOI: https://doi.org/10.1053/j.jvca.2020.04.054.

21. Pedersen T, Nicholson A, Hovhannisyan K, Mфller AM, Smith $A F$, Lewis SR. Pulse oximetry for perioperative monitoring. Cochrane Database Syst Rev 2014; DOI: https://doi.org/10.1002/ 14651858.CD002013.pub3.

22. MacKay EJ, Neuman MD, Fleisher LA, et al. Transesophageal echocardiography, mortality, and length of hospitalization after cardiac valve surgery. J Am Soc Echocardiogr 2020; 33(756-62): e1.

23. Robitaille A, Denault AY, Couture P, et al. Importance of relative pulmonary hypertension in cardiac surgery: the mean systemicto-pulmonary artery pressure ratio. J Cardiothorac Vasc Anesth 2006; 20: 331-9.

24. Schuurman $P R$, Albrecht $K W$. Intraoperative changes of transcranial Doppler velocity: relation to arterial oxygen content and whole-blood viscosity. Ultrasound Med Biol 1999; 25: 151-4.

25. Kampfl A, Pfausler B, Denchev D, Jaring HP, Schmutzhard E. Near infrared spectroscopy (NIRS) in patients with severe brain injury and elevated intracranial pressure. A pilot study. Acta Neurochir Suppl 1997; 70: 112-4.

26. Alosh H, Ramirez A, Mink R. The correlation between brain nearinfrared spectroscopy and cerebral blood flow in piglets with intracranial hypertension. J Appl Physiol 1985; 2016(121): 25560.

Publisher's Note Springer Nature remains neutral with regard to jurisdictional claims in published maps and institutional affiliations. 